\title{
Photovoltaic Powered Reverse Osmosis Plant for Brackish Water without Batteries with Self Acting Pressure Valve and MPPT
}

Doglasse Ernesto Mendonça ${ }^{1,3}$, Paulo César Marques de Carvalho ${ }^{1}$, Paulo Peixoto Praça ${ }^{1}$, José Sigefredo Pinheiro Neto $^{1}$ and Douglas Bressan Riffel ${ }^{2}$

1. Department of Electrical Engineering, Federal University of Ceará - UFC, Fortaleza, 60455-760, Brazil

2. Department of Mechanical Engineering, Federal University of Sergipe - UFS, Sao Cristovão, Sergipe 49100-000, Brazil

3. Department of Engineering, Pedagogical University - UP, Km 1, Maputo, Mozambique

Received: June 14, 2016 / Accepted: June 23, 2016 / Published: March 31, 2017.

\begin{abstract}
This paper presents a PV (photovoltaic) powered RO (reverse osmosis) plant for brackish water without batteries and a self-regulating pressure valve. The aim is to extract the maximum power from the PV module using an MPPT (maximum power point tracking) technique for powering a solar water pump and maintain constant the pressure in the RO membranes by using the self-operated valve. A Buck type converter using the InCond (incremental conductance) MPPT was developed for this application. The MPPT chosen was simulated, tested and validated, showing an efficiency of $86.8 \%$. The technical feasibility of the RO plant was made by PLC (programmable logic controller) and was tested for two salinity levels (1,000 and 1,500 mg/L of TDS (total dissolved solids)). These salinity levels chosen are commonly found in most brackish water wells of the semi-arid region of Northeastern Brazil. The RO plant could permeate $175.3 \mathrm{~L} /$ day of drinking water with $120 \mathrm{mg} / \mathrm{L}$ of TDS and specific energy consumption of $2.56 \mathrm{kWh} / \mathrm{m}^{3}$.
\end{abstract}

Key words: Reverse osmosis, maximum power point tracker, solar energy.

\section{Introduction}

Water has a critical contribution to all aspects of personal welfare and economic life. However, global water resources are coming under increasing pressure from growing human demands and climate change. However, only about $2.7 \%$ of all the water resources are potable, while about $25 \%$ of the world's population does not have access to adequate quality and quantity of fresh water [1].

According to UN (United Nations) in the WWDR (world water development report) 4, 2015, in 15 years, the water crisis worsened all over the world and it states that poorest will suffer most of the consequences

Corresponding author: Doglasse Ernesto Mendonça, M.Sc., lecturer, research fields: power electronics, desalination systems, renewable energy, embedded digital systems. of this process [2]. Thus, the desalination of seawater and brackish appears as a viable option to address water scarcity and ensure a reliable supply of drinking water.

Desalination is a general term for the process of removing salt from water to produce fresh water. Fresh water is defined as containing less than $1,000 \mathrm{mg} / \mathrm{L}$ of salts or TDS (total dissolved solids) [3].

The major two desalination methods are distillation (boiling and condensation) and the RO (reverse osmosis) process. The RO system uses a fine membrane that allows pure water to pass through while rejecting the large salt molecules. This is achieved by pressurizing the seawater to about 60 bars and then to force the water through the mechanical constriction presented by the membrane against the natural osmotic pressure. 
The major costs in desalination are related to energy which can represent between $30 \%$ and $50 \%$ of the operating costs [4]. To improve system efficiency and reduce cost of the system was developed a step-down direct current (DC-DC) Buck type converter controlled by an MPPT algorithm for connecting to the pump responsible for pressurizing water to the RO membranes and a self-regulating pressure valve in the concentrate.

The technical feasibility of the system was made with the PLC (programmable logic controller) that allowed the acquisition of desalination plant data.

\section{Brackish Water RO Plant Design}

The RO plant, shown schematically in Fig. 1, consists of four storage tanks of 310 litres each.

\subsection{Self-regulating Pressure Valve}

The self-regulating pressure valve in Fig. 2, is actuated by a pressure responsive diaphragm, which seeks to reach equilibrium between hydraulic and set spring force.

Supplied with a special throttling plug and elastomeric seal, it reduces higher upstream pressure to lower constant downstream pressure. The valve was installed in the concentrate line.

The Upstream Pressure (P1) applies balanced opening and closing hydraulic forces under the Diaphragm 1 and above the Plug (2). Downstream Pressure (P2) applies hydraulic closing force under the

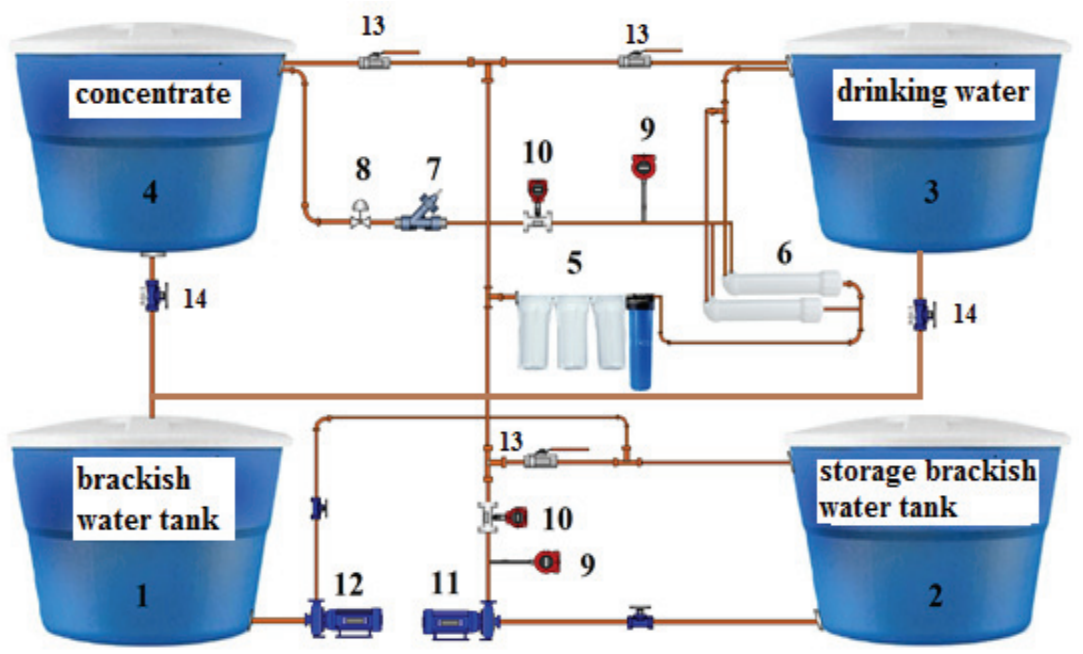

Fig. 1 RO configuration plant.

1 - Brackish water tank; 2 - Storage brackish water tank; 3 - Drinking water; 4 - Concentrate; 5 - Pre-treatment block (sediment filter, carbon filter, deionizer filter); 6 - TW30-1812-100 RO membranes; 7 - Self-regulating pressure valve (Bermad valves type); 8 Manual valve; 9 - Pressure meter; 10 - Flow meter; 11 - Solar water pump SHURFLO 8000; 12 - Solar water pump SHURFLO 2088; 13 and 14 - Manual valve (nomal closed valve and used only for backwasher).

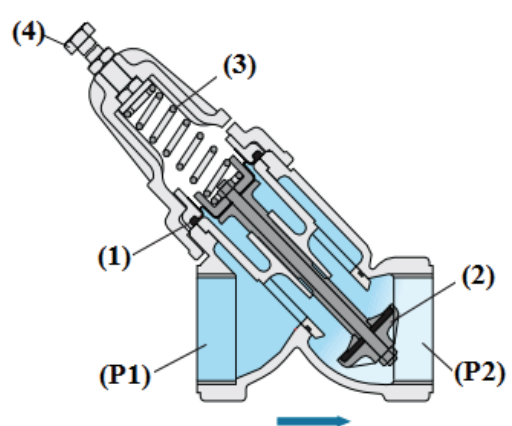

Fig. 2 Self acting pressure valve schematic. 


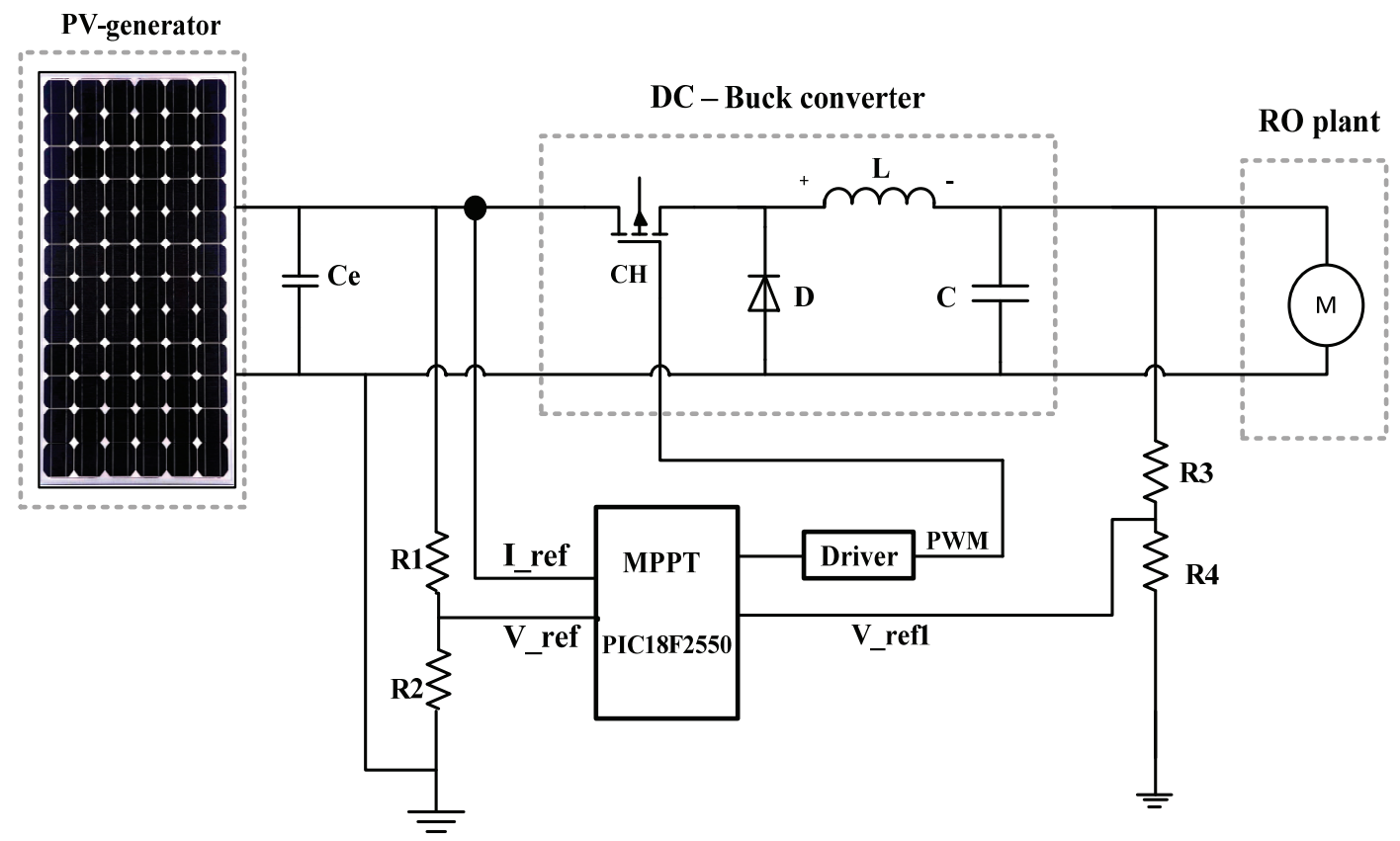

Fig. 3 Block diagram of the PV-RO with MPPT developed.

plug, which seeks to reach equilibrium with the Set Spring (3) force. Should (P2) rise above setting, the hydraulic closing forces rise above the mechanical force of the spring, pushing the plug to modulate closed, reducing (P2) back to setting, and eventually shutting drip-tight.

The setting screw (4) is used to adjust the maximum operated pressure.

\section{Photovoltaic System for RO (PV-RO)}

The photovoltaic system for powering the desalination plant is designed according to the block diagram in Fig. 3. Consists of 1 PV module $160 \mathrm{~W}$, a DC-DC Buck type converter of $160 \mathrm{~W}$, which was developed especially for this application, 2 hall current sensors ACS712, 2 voltage sensors of the resistive divider $(\mathrm{R} 1=150 \mathrm{k} \Omega, \mathrm{R} 2=18 \mathrm{k} \Omega, \mathrm{R} 3=75 \mathrm{k} \Omega$ and $\mathrm{R} 4$ $=27 \mathrm{k} \Omega$ ), a driver for signal conditioning, a PIC18F2550 microcontroller, responsible for implementing the MPPT code, an Inductor $(\mathrm{L}=320$ $\mu \mathrm{H})$, an MOSFET (CH-IRFP064N), a diode (D-MBR1535CT). I_ref, V_ref, V_ref1 are the currents and voltage reference, $M$ is solar water pump and the capacitors are $\mathrm{Ce}=4 \times 470 \mu \mathrm{F}$ and the output capacitor $\mathrm{C}=2 \times 470 \mu \mathrm{F}$.

\subsection{MPPT for $P V$}

The operating point of a photovoltaic generator that is connected to a load is determined by the intersection point of its characteristic curves. In general, this point is not the same as the generator's maximum power point. This difference means losses in the system performance $[5,6]$. The efficiency of the system can be improved if the PV array is operated intentionally at the MPP (maximum power point), irrespective of varying atmospheric conditions. An MPPT is used for extracting the maximum power from the solar PV module and transferring that power to the load. A $\mathrm{DC} / \mathrm{DC}$ converter serves the purpose of transferring maximum power from the solar PV module to the load. A DC/DC converter acts as an interface between the module and the load. It is responsible to change the duty cycle by matching the load impedance at the MPP [7]. Therefore, MPPT techniques are needed to maintain the PV array's operating at its MPP [8]. A large number of conventional MPPT techniques, have been reported in Ref. [9]. In this project, the InCond (incremental conductance) method was used, and 
algorithm code was written according to the flow chart of Fig. 4. This strategy is based on the fact that the slope of power-voltage curve is zero at the maximum point $(d P / d V=0$ and $P=V \cdot I)$. According to this condition, the MPP can be found in terms of PV array conductance increment. Eq. (1) for the slope $d P / d V$ at MPP is given by:

$$
\frac{d P}{d V}=\frac{d}{d V}[V \cdot I]=I+V \cdot \frac{d I}{d V}=I+V \cdot \frac{\Delta I}{\Delta V}
$$

Therefore, by evaluating the derivative of Eq. (1), the method can test whether the PV generator is operating at near MPP or far away from it using conditions of Eq. (2).

$$
\begin{gathered}
\left\{\begin{array}{l}
d P / d V=0 \\
d P / d V>0 \\
d P / d V<0
\end{array}\right. \\
\rightarrow\left\{\begin{array}{c}
\Delta I / \Delta V=-I / V \text { at } M P P \\
\Delta I / \Delta V>-I / V \text { left of } M P P \\
\Delta I / \Delta V<-I / V \text { right of } M P P
\end{array}\right.
\end{gathered}
$$

where, $P, I$ and $V$ are the PV array output power, voltage and current, respectively. Discreetly are represented by $I(n)$ and $V(n)$. Where $\Delta I$ and $\Delta V$ can be obtained by the Eqs. (3) and (4).

$$
\begin{gathered}
\Delta I=I(n)-I(n-1) \\
\Delta V=V(n)-V(n-1)
\end{gathered}
$$

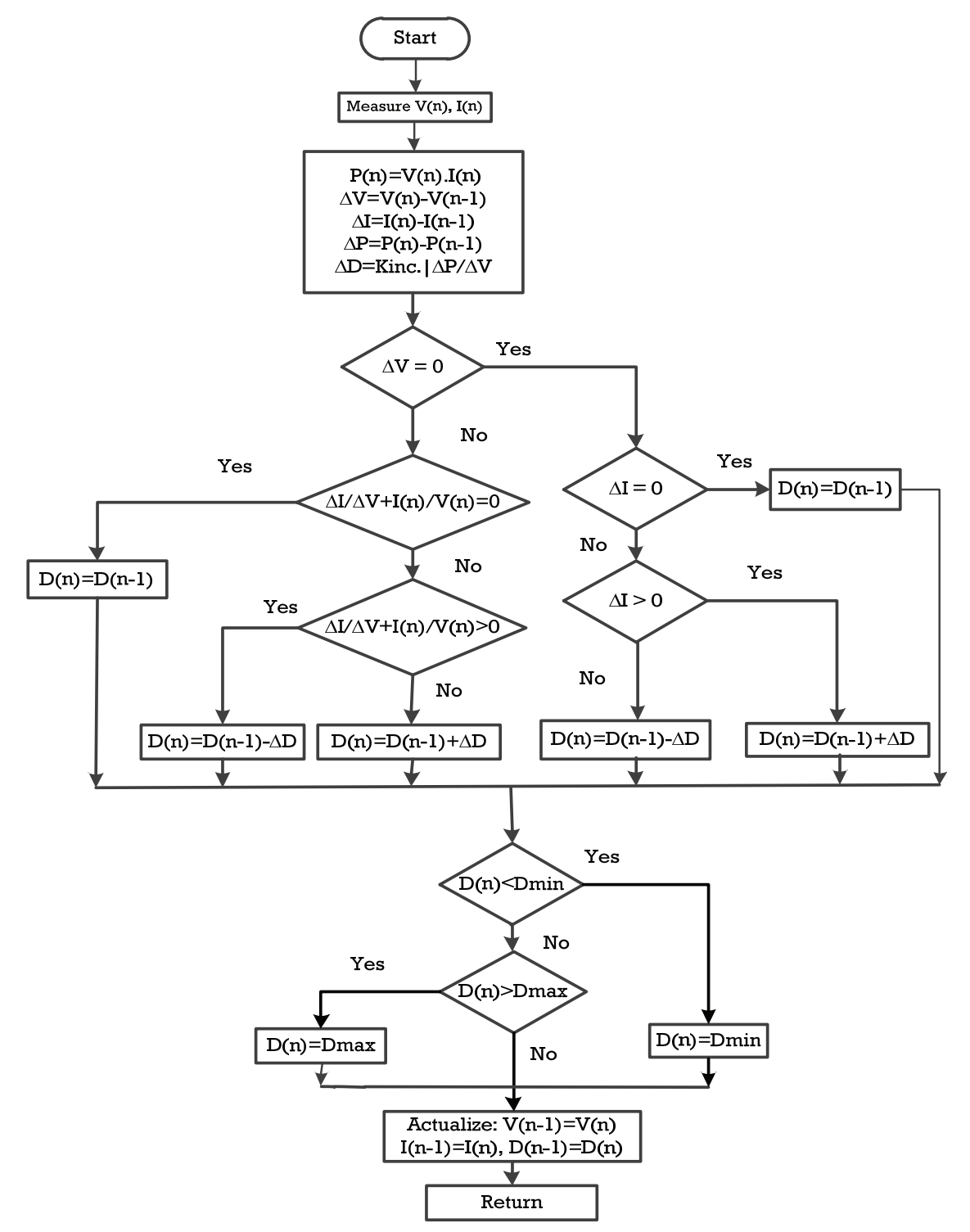

Fig. 4 INC algorithm. 
Table 1 Specifications and considerations of the power unit.

\begin{tabular}{ll}
\hline MPP power, $P_{\mathrm{MPP}}$ & $160 \mathrm{~W}$ \\
MPP voltage, $V_{\mathrm{MPP}}$ & $35.25 \mathrm{~V}$ \\
MPP current, $I_{\mathrm{MPP}}$ & $4.54 \mathrm{~A}$ \\
Rated output voltage, $V_{\text {Load }}$ & $12 \mathrm{~V}$ \\
Frequency switching, $f_{s}$ & $20 \mathrm{kHz}$ \\
Voltage ripple, $\Delta V$ & $10 \%$ \\
Current ripple, $\Delta I$ & $10 \%$ \\
\hline
\end{tabular}

\section{Specifications and Power Unit Design Considerations}

The power unit for this application was developed taking consideration of PV module specifications and solar water pump specifications. Table 1 shows the specifications of the power unit.

To obtain the main equation that shows how the converter find MPP, the current and voltage gain of the buck converter should be obtained using the Eqs. (5) and (6) [10].

$$
\begin{gathered}
V_{\text {Load }}=D \cdot V_{P V} \\
\frac{I_{\text {Load }}}{I_{P V}}=\frac{1}{D}
\end{gathered}
$$

Combining Eqs. (5) and (6) by relational substitutions, we arrive at Eq. (7), showing how the converter can stop the load line at the maximum power point by varying the duty cycle (D).

$$
R_{e i}\left(D, R_{\text {load }}\right)=\frac{R_{\text {Load }}}{D^{2}}
$$

where, $I_{\text {Load }}$ is the current that passes thought the load, $I_{\mathrm{PV}}$ is $\mathrm{PV}$ output current; $V_{\mathrm{PV}}$ is $\mathrm{PV}$ output voltage, $R_{\mathrm{Load}}$ is the impedance; $R_{e i}$ is the input effective resistance, which is variable.

\section{Implementation Design}

The power unit prototype, a DC-DC Buck converter, developed is shown in Fig. 5. The board was developed at the laboratory of GPEC (Control and Energy Processing Group) of the DEE-UFC (Electrical Engineering Department-Federal University of Ceará), and was subsequently installed in the desalination plant of the LEA (Alternative Energy Laboratory) of the
UFC. According to Fig. 5, the developed power unit is composed of: 1-PV input, 2-output voltage, 3-microcontroller PIC 18F2550, 4-A3120 driver, 5-inductor, 6-MOSFET, 7-diode, 8-current sensor, 9 -voltage sensor.

\subsection{Photovoltaic Module}

The PV module (AZUR TSM 160) is installed at the roof of LEA, approximately $15^{\circ}$ of geographic north as shown in Fig. 6.

\subsection{Brackish RO Plant}

The RO plant used, showed in Fig. 7, consists of four fiberglass tanks. For environmental reasons the tanks are interconnected in a closed system, so that the permeate and concentrate flows return to the tank.

\section{System Validation}

To validate the developed power unit, three steps were performed:

(1) A tracer mini-KLA model was used to obtain the MPP of the PV module curve for different levels of irradiance and temperature.

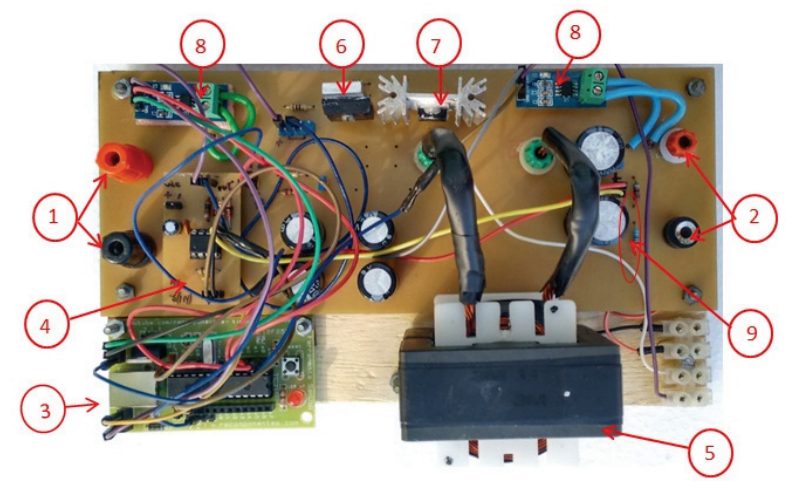

Fig. 5 Buck prototype.

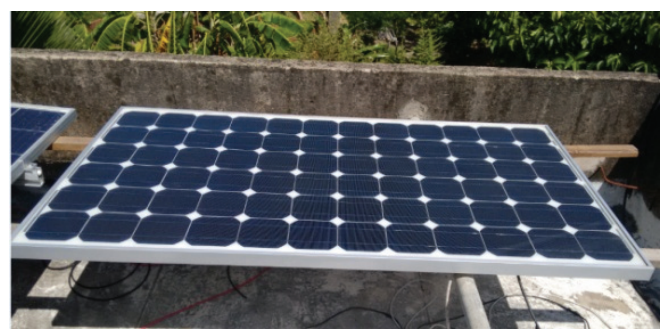

Fig. 6 PV module used. 


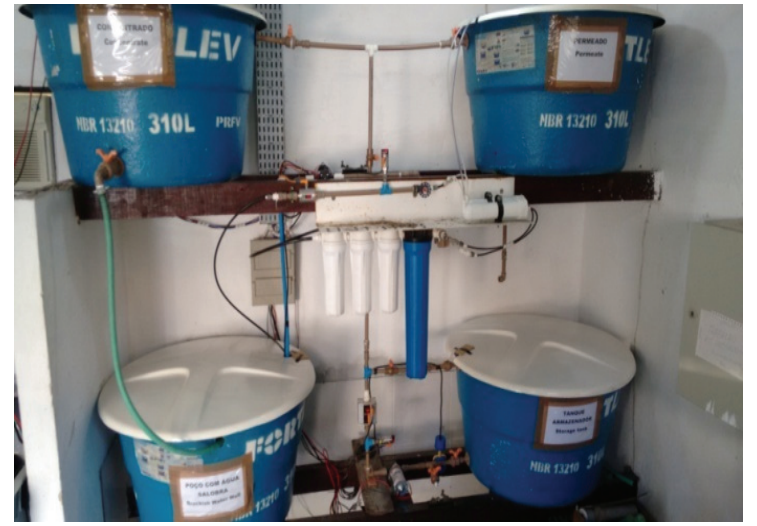

Fig. 7 RO plant developed.

(2) The developed power unit was connected to a resistive load consisting of three dichroic lamps of 50 $\mathrm{W} / 12 \mathrm{~V}$ connected in parallel and the power unit efficiency was calculated by Eq. (8).

$$
\eta=\left(1-\frac{P_{\operatorname{maxT}}-P_{\text {load }}}{P_{\operatorname{maxT}}}\right) \cdot 100
$$

where, $\eta$ is the efficiency; $P_{\max }$ is the maximum power measured by the tracer; $P_{\text {load }}$ is the power in the load.
A measured and estimated value for the steps taken to validate the method chosen is shown in Table 2. The MPPT efficiency was calculated by Eq. (8) [11].

Fig. 8 shows the validation of the MPPT where the INC method chosen showed $86.8 \%$ of efficiency in average. We could find out that even for low levels of irradiance, such as $200 \mathrm{~W} / \mathrm{m}^{2}$, the power unit was capable of supplying the rated power for the solar pump.

(3) The PV system was connected to the RO plant and tested for two desalination salt concentration levels of about 1,000 to $1,500 \mathrm{mg} / \mathrm{L}$ TDS. These salt levels are found on most of the brackish water wells of semi-arid regions, especially in northeastern Brazil [12]. The variation of the two salt levels was made by addition of sodium chloride $\mathrm{NaCl}$ (cooking salt) in the well tank.

The tests were carried out at the plant in two clear sky days. The results obtained for two days and two salt concentration levels are summarized in Table 3.

Table 2 Validation of the MPPT - 16/09/2015.

\begin{tabular}{|c|c|c|c|c|c|c|}
\hline \multirow[b]{2}{*}{ Irradiance $\left(\mathrm{W} / \mathrm{m}^{2}\right)$} & \multirow{2}{*}{$\begin{array}{l}\text { Ambient Temp. } \\
(\mathrm{K})\end{array}$} & \multicolumn{3}{|c|}{ Electrical characteristics of the PV module } & \multicolumn{2}{|c|}{ MPPT } \\
\hline & & $I_{\mathrm{MP}}(\mathrm{A})$ & $V_{\mathrm{MP}}(\mathrm{V})$ & $\begin{array}{l}P_{\operatorname{maxT}}, \\
P_{\text {MP PV }}(\mathrm{W})\end{array}$ & $P_{\mathrm{INC}}(\mathrm{W})$ & Efficiency $(\%)$ \\
\hline$[230-260]$ & 308.75 & 1.06 & 31.44 & 33.31 & 30.99 & 93.0 \\
\hline [308-380] & 320.05 & 1.38 & 31.15 & 43.03 & 41.74 & 97.0 \\
\hline$[402-490]$ & 320.65 & 1.82 & 30.64 & 55.79 & 43.24 & 77.5 \\
\hline$[550-620]$ & 332.85 & 2.6 & 29.93 & 77.84 & 67.02 & 86.1 \\
\hline [650-690] & 340.05 & 2.71 & 29.23 & 79.402 & 75.31 & 94.8 \\
\hline$[700-800]$ & 341.65 & 3.36 & 27.44 & 95.59 & 79.42 & 83.1 \\
\hline [865-950] & 341.95 & 3.92 & 27.9 & 109.47 & 88.68 & 81.0 \\
\hline$[985-1,000]$ & 342.25 & 4.13 & 27.95 & 115.34 & 96.64 & 83.8 \\
\hline$[1,005-1,015]$ & 342.45 & 4.59 & 27.09 & 124.32 & 105.67 & 85.0 \\
\hline
\end{tabular}

Table 3 Average results of the RO plant performance.

\begin{tabular}{lll}
\hline Date operation & $1 / 12 / 2015$ & $2 / 12 / 2015$ \\
\hline Feed water TDS (mg/L) & 1,561 & 1,095 \\
Drinking water TDS (mg/L) & 143 & 98 \\
Drinking water production (L/day) & 179.24 & 171.37 \\
Energy consumption $\left(\mathrm{kWh} / \mathrm{m}^{3}\right)$ & 2.52 & 2.60 \\
Working pressure $(\mathrm{psi})$ & 47.14 & 46.4 \\
Daily operation (h/day) & 9.0 & 9.26 \\
Water temperature $(\mathrm{K})$ & 302.8 & 301.95 \\
Daily irradiation $\left(\mathrm{kWh} / \mathrm{m}^{2}\right)$ & 5.69 & 5.96 \\
Salt rejection $(\%)$ & 90.8 & 91.1 \\
Recovery rate $(\%)$ & 8.62 & 7.66 \\
\hline
\end{tabular}




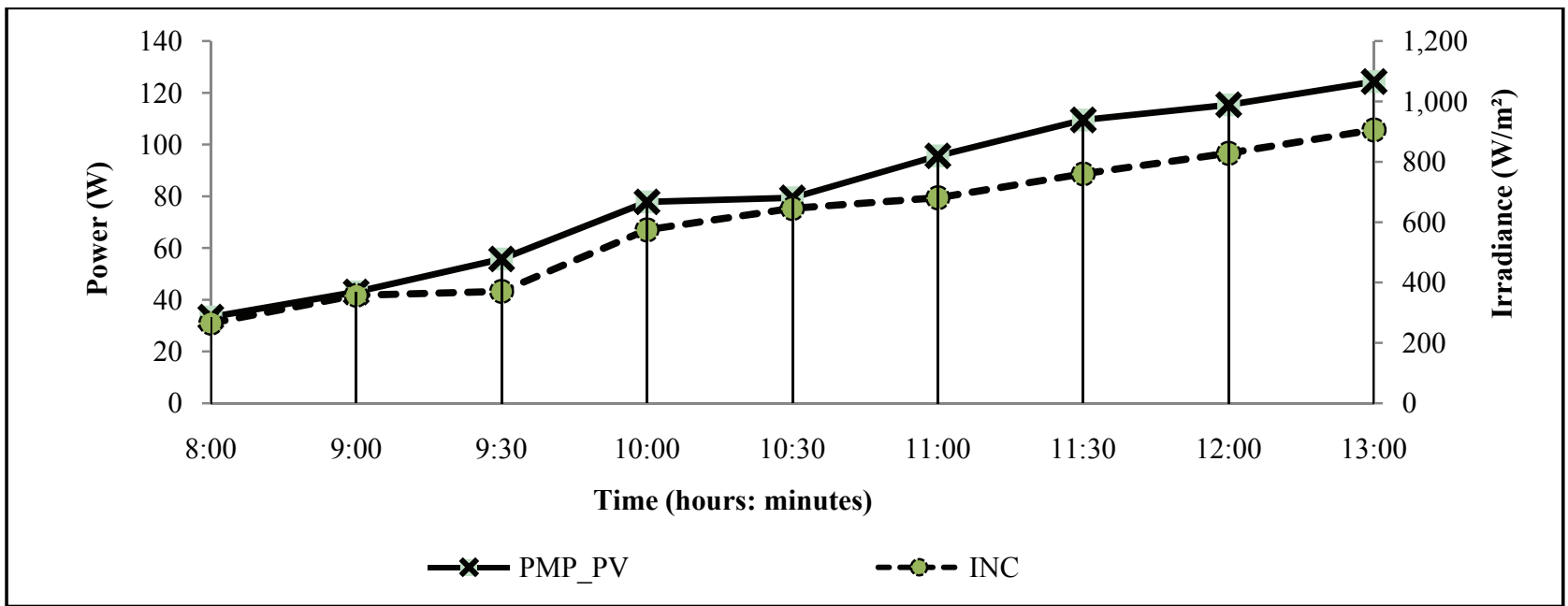

Fig. 8 Validation of MPPT.

\section{Conclusions}

Optimizing the use of solar energy has become a very important topic for improving efficiency in systems powered by this type of power source and therefore cost savings. One way to reduce costs of this form of energy generation is the use of MPPT algorithms and DC-DC converters without the use of batteries. In this project we developed a Buck type converter using INC algorithm for MPPT. The algorithm used reached $86.8 \%$ of efficiency in average. The improvement achieved can contribute to technical feasibility of this type of system.

The uses of Buck converter with MPPT extend the plant time operation. For both levels of salt concentration $(1,000$ and 1,500) $\mathrm{mg} / \mathrm{L}$ TDS used in RO desalination plant it was able to permeate $175.3 \mathrm{~L}$ of daily production of drinking water with $120 \mathrm{mg} / \mathrm{L}$ of TDS, specific energy consumption of $2.56 \mathrm{kWh} / \mathrm{m}^{3}$.

Solar PV energy coupled to the desalination shows an efficiency that can be applied to rural areas where the water scarcity is severe.

\section{Acknowledgement}

The first author would like to acknowledge financial support of National Counsel of Technological and Scientific Development, CAPES, Federal University of Sergipe-UFS, FIPATEC/SE (research and technological innovation foundation of Sergipe) also gratefully acknowledge support of LEA (Alternative Energy Laboratory) members.

\section{References}

[1] Koutroulis, E., and Kolokotsa, D. 2010. "Design Optimization of Desalination Systems Power-Supplied by PV and W/G Energy Sources.” Desalination 258 (1-3): 171-81.

[2] WWAP (World Water Assessment Programme). 2012. World Water Development Report Volume 4: Managing Water under Uncertainty and Risk.

[3] Greenlee, L. F., Lawler, D. F., Freeman, B. D., Marrot, B., and Moulin, P. 2009. "Reverse Osmosis Desalination: Water Sources, Technology, and Today's Challenges." Water Research 43 (9): 2317-48.

[4] Burn, S., Hoang, M., Zarzo, D., Olewniak, F., Campos, E., Bolto, B., and Barron, O. 2015. "Desalination Techniques -A Review of the Opportunities for Desalination in Agriculture." Desalination 364 (May): 2-16.

[5] Enrique, J. M., Durán, E., Sidrach-de-Cardona, M., and Andújar, J. M. 2007. "Theoretical Assessment of the Maximum Power Point Tracking Efficiency of Photovoltaic Facilities with Different Converter Topologies." Solar Energy 81 (1): 31-8.

[6] De Carvalho, P. C. M., Pontes, R. S. T., Oliveira, D. S. J., Riffel, D. B., De Oliveira, R. G. V., and Mesquita, S. B. 2004. "Control Method of a Photovoltaic Powered Reverse Osmosis Plant without Batteries Based on Maximum Power Point Tracking." In Proceedings of the IEEE PES Transmission and Distribution Conference and Expo, 137-42.

[7] Yadav, A., and Thirumaliah, S. 2012. "Comparison of MPPT Algorithms for DC-DC Converters Based PV Systems." International Journal of Advanced Research in Electrical, Electronics and Instrumentation Engineering 1 


\section{Pressure Valve and MPPT}

(1): 476-81.

[8] Dolara, A., Faranda, R., and Leva, S. 2009. "Energy Comparison of Seven MPPT Techniques for PV Systems." Journal of Electromagnetic Analysis and Applications 1 (3): 152-62.

[9] Bhatnagar, P., and Nema, R. K. 2013. "Maximum Power Point Tracking Control Techniques: State-of-the-Art in Photovoltaic Applications." Renewable and Sustainable Energy Reviews 23 (July): 224-41.
[10] Hart, D. W. 2011. Power Electronics.

[11] Salah, C. B., and Ouali, M. 2011. "Comparison of Fuzzy Logic and Neural Network in Maximum Power Point Tracker for PV Systems." Electric Power Systems Research 81 (1): 43-50.

[12] de Oliveira, R. S. H. 2011. "Planta Laboratorial de Dessalinização via Osmose Reversa Alimentada por Energia Solar Fotovoltaica com Ou Sem Baterias." Universidade Federal do Ceará , Fortaleza. 